\title{
Remote Teaching in Professor Training: Three Latin American Experiences in Times of COVID-19 Pandemic
}

\author{
Orlando Fernández Aquino ${ }^{1, * \mathbb{D}}$, Patricia Medina Zuta ${ }^{2}$ and Eldis Román Cao ${ }^{3}(\mathbb{D}$ \\ 1 Postgraduate Program in Education, University of Uberaba, Uberaba 1801, Brazil \\ 2 Postgraduate School, Antonio Ruiz de Montoya University, Lima 15084, Peru; patricia.medina@usil.pe \\ 3 Faculty of Philosophy, Letters and Educational Sciences, Technical University of Manabí, \\ Portoviejo 130105, Ecuador; eldis.roman@utm.edu.ec \\ * Correspondence: orlando.aquino@uniube.br
}

Citation: Aquino, O.F.; Zuta, P.M.; Cao, E.R. Remote Teaching in Professor Training: Three Latin American Experiences in Times of COVID-19 Pandemic. Educ. Sci. 2021, 11, 818. https://doi.org/10.3390/ educsci11120818

Academic Editors: Eila Jeronen and Randall S. Davies

Received: 19 August 2021

Accepted: 2 December 2021

Published: 16 December 2021

Publisher's Note: MDPI stays neutral with regard to jurisdictional claims in published maps and institutional affiliations.

Copyright: (c) 2021 by the authors. Licensee MDPI, Basel, Switzerland. This article is an open access article distributed under the terms and conditions of the Creative Commons Attribution (CC BY) license (https:/ / creativecommons.org/licenses/by/ $4.0 /)$.

\begin{abstract}
The subject matter has been based on three systematizations of experiences in teacher training through remote teaching, during the COVID-19 pandemic of 2020-2021. They were developed in IES in Brazil, Ecuador, and Peru. The objective has been to show the experiences implemented to build the teachers' pedagogical knowledge, from online teaching practices. The theoretical framework has been the theory of collaborative and developmental learning, according to L. S. Vigotski and his followers. The work methodology has been the systematization of experiences, according to Jara and others. The results of the Brazilian experience show how it is possible for students of the degree in pedagogy to acquire didactic knowledge and develop skills, through collaborative work in virtual rooms. The Ecuadorian experience shows the effectiveness of teaching focused on autonomous work, which is based on asynchronous activities. The results of the experience in Peru show how asynchronous accompaniment is an effective means for guidance and sustained feedback by the trainer, with an impact on the process of construction of a scientific text and on the productivity of the doctoral student in Education.
\end{abstract}

Keywords: teacher training in times of COVID-19; remote teaching; systematization of experiences; developer learning

\section{Introduction}

This article presents three teaching experiences of university professors from Brazil, Ecuador, and Peru, respectively. These experiences focus on professor training through online remote teaching, at undergraduate and postgraduate levels. They were developed in three universities in these countries, from March 2020 through a portion of 2021, just in the middle of the COVID-19 pandemic. The authors of this article are also the professors who developed these experiences.

It is considered that recounting these experiences, making them available to the scientific community, conveys a high historical and pedagogical value for present and future generations of professors. The serious public health and educational crisis that the COVID-19 pandemic has caused in Latin America, as well as in other regions of the world, led most teachers to make an extraordinary professional and creative effort to move from face-to-face teaching to remote or hybrid teaching, with the insertion of Information and Communication Technologies (ICTs) means. Among the great challenges were the professors' prompt involvement in the use of ICTs, their effective didactic use to create virtual learning environments being developmental and collaborative, and the increase of sensitivity, solidarity, and ethical-professional responsibility. All this justifies, in summary, what is being displayed in this kind of paper.

Thus, the addressed scientific object has been the professors' training at the undergraduate and graduate levels, by means of remote teaching, in three Latin American universities, during the COVID-19 pandemic of 2020-2021. The question to be answered is 
the following: What are some of the pedagogical solutions found by professors' trainers, at postgraduate and undergraduate levels, in three Latin American universities to make remote teaching effective, with the help of ICTs, creating virtual development-oriented learning environments and focused on online collaborative work of future professors, in the period of the COVID-19 pandemic in 2020-2021?

Accordingly, the objective is to present the experiences implemented to build up the pedagogical knowledge of professors and student teachers, from online teaching practice, during the 2020-2021 period of the COVID-19 pandemic.

The studies are based on the theory of developmental and collaborative learning, within the perspective of a historical-cultural approach, whose authors are classics of psycho-pedagogy, such as: [1-13].

The general methodology has been based on the description or systematization of experiences, supported by authors of internationally acclaimed prestige in this field, including [14-18]. In each of the reported experiences, results are assessed, and their final considerations are presented.

The experiences described above, each with its own particularities, show that remote teaching offers professors many computer tools for their work organization, although it is difficult for a professor to master all of them, which is not necessary either. In other words, mastering the ones that best suit their needs and work method would be enough to motivate students and set them to work in a cooperative and developmental way to solve learning issues.

These experiences are the result of a joint international effort of researchers of the REED/Education Studies Network (https: / / www.reed-edu.org, accessed on 2 July 2021), through which a line of argument and academic results are developed, thus contributing to the increase of educational scientific knowledge in Latin America. On the other hand, the studies have a social and pedagogical impact because they show the feasibility for online remote teaching for professor training in Latin American universities, both in initial and post-graduation training, in view of a new social and educational reality the world is facing in the context of a COVID-19 post-pandemic.

\section{Theoretical Framework}

The systematized experiences in this article were mainly based on the theory of developmental and collaborative learning. In a move of abstraction and generalization, and for the sake of summing up, we formulate below some theses of this theory, based on cited sources.

In this approach, the theory of collaborative and developmental learning is anchored in the contributions of the Historical-Cultural Theory [1,2]; in the Activity Theory [3,4]; in the Theory of the Formation of Mental Actions and Concepts $[11-13,16]$ and in the Theory of Study Assignment [8-13,19,20], among other authors of international significance. This conceptual framework is attained as an open theory, in a systematic dialogue with others of its kind, and enhanced with each new socio-educational experience.

It is considered that, in adequate living and educational conditions, a student's development is understood as self-development. Development is not imposed from the outside in, but as a self-transformation and as a self-education. This takes place under pedagogical conditions in which students are challenged to solve problems and learning tasks, individually and collectively. Development comes into being in the appearance of the new, in neoformations, skills, in the scientific concept formation. It is expected that schools being able to promote the formation of the theoretical thinking in students. It must deal with both ordinary and scientific concepts (they are a dialectical unit). However, highly developed thinking is a product of the formation of theoretical thinking. Theoretical thinking grasps and synthesizes the essential and universal links that define which are the objects, concepts, and processes of the social and natural reality. These scientific concepts become thinking tools for the solution of issues in the practical, cultural, and scientific life of society. 
The theory of developmental learning focuses on psychic, intellectual and emotional development (the cognitive-affective unity). It is based on the notion that the development of psychological neoformations is only possible while taking place in a subjectivized manner, in other words, in the unity of symbolism and emotion.

Learning leading to development takes place in the context of the Zone of Proximal Development [1], in which the more experienced subjects (students, professors, parents) provide the necessary levels of assistance for the progress of those less advantaged, in an educational environment in which everyone learns, although each at his or her own pace. Developmental learning is oriented towards tomorrow's development and not towards yesterday or today. It is based on the thesis of [1] stating that adequate learning anticipates and guides development. Learning is the universal way for the development of learners.

For learning to become developmental, a student must design the study assignment [9,11-13]. This is devised by means of a set of actions and operations to find the solution of study tasks for various school subjects. It is a specific human activity such as work, scientific or sports activity, but it has its own conception and training processes $[5,10]$. The study assignment has a specific training-developmental function, it has its own structure and dynamics among its components. It is different from other human activities by its content: study. Outside the study assignment, it is not possible to put into practice developmental and collaborative learning. This type of learning is a dialectical overcoming of learning notions spread out by positivist, biologist, and structuralist theories.

The theory of developmental and collaborative learning focuses on the learner's comprehensive development: being emotional, cognitive, moral, aesthetic, and physical. The development of the learner's personality is not only a prerequisite, but also a process and a product brought together. The theory of developmental and collaborative learning considers the contents and methods of learning but focuses on the development of the learner. Would it be possible to speak of subject didactics, since the subject is understood as the subject and object of his own learning and development, and not as a static instance, as something concrete? It is proven that, in the process of study, the student's personality takes shape until the student emerges as an active subject of his own transformation. As studies progress and there is a more elaborated theory of the subject, who knows if we could then speak of a subject.

\section{Methodology: Systematization or Experience Recounting}

The preparation of this article was based on the methodology of systematization or recounting of experiences. Teaching experiences, when meaningful and well reported, contribute to the understanding of teachers' practical knowledge, and raise the quality of education. The student teacher's participation in such experiences allows them to reach higher levels of competencies, as well as their social and professional participation. It enables them to handle better their profession, in accordance with their training and living conditions. Similarly, the Colombian Ministry of National Education emphasizes that: "[ ... ] the socialization, feedback and follow-up of experiences are not only strategies to recognize and dignify the teachers' performance, but also allow for a judicious accompaniment for the educational community being benefited" [16] (p. 39).

Nóvoa [17] states that modernity stripped educational providers from their subjectivities since it led them to acquire a structural logic and a reasoning as a community. Educational providers were classified by categories: professors, students, managers, parents, and these were managed as communities. The author explains that historians of education, after having considered the world as a structure and a representation, now need to see it as an experience, which implies a new epistemology in the subject approach.

The concept of experience does not refer only to a simple 'living events', but also encompasses the way in which 'people built up events as they lived them' (Sewell, 1990). [ . . . T There is a strong appeal in a theory that allows us to elucidate the complex cultural construction of people's lives and experiences." [17] (Apud. p. 33). 
Thus, valuing experience does not mean a return to individualism. Rather, it is about establishing new relationships and attachments within social spaces, which humanizes us and makes us be better. The concept of experience, seen in the dynamics from the individual and social approach, implies a redefinition of identities, inserting subjects in different communities of meaning. This means that the current science of education needs to redefine the concepts of subject and experience, thus allowing an understanding not only from the experience itself, but also from the way in which it is presented by the subjects who elaborate it. This is so, because the production of narratives by the key subjects produces counter-hegemonic texts, configures emancipatory identities, and decolonizes our minds.

For [18] (p. 12): "Systematization is a valuable resource for 'looking at oneself', for being critical, for recognizing progress and continuing to learn. It brings together reflection on one's own experience and is an opportunity to grow professionally". As a process of reflection, systematization organizes facts and results of a project, seeking the dynamics of the dimensions involved in the work carried out by professors.

In terms of UNESCO's perception [18], systematization enhances to improve learning, verify the changes generated in professors and schools, improve, and transform experiences through the critical analysis of teaching practice and student learning, and identify projections guaranteeing the sustainability of policies and strategies at different levels. For Colombia-MIN [3], the systematization of experiences is:

[... ] a permanent process of thinking and reflective writing about the practice and knowledge of significant experiences [ ... ] an opportunity to rebuild practice, learn from what has been done, build up meaning, improve the understanding of what has been done and find ways to let others know, to generate processes of transfer, adaptation, and construction of knowledge, based on the provided lessons. [16] (p. 12).

In this regard, the systematization of experiences helps to improve knowledge about what is accomplished in educational institutions, to refine the experience and reflections that provide the best results, to empower the subjects who participate in the experience and to go beyond the context by extending knowledge to other educational scenarios. For his part, Jara [15], states that:

The systematization of experiences is an intentional exercise that seeks to penetrate the near-complex fabric of experience and recreate its knowledge with an interpretative exercise of theorization and conscious appropriation of what has been experienced. It requires a commitment to epistemological curiosity and assumes methodical rigor to convert knowledge coming out from experience [ ... ] into critical knowledge [... ] The systematization of experiences allows us to link the reflection that emerges from what we experience with other theoretical approaches, to understand it, beyond pure description or immediacy [ ... ]. [15] (p. 55).

This Jera's concept [15] is striking due to its depth and pinpointing at essential aspects of systematization, such as: the interpretative exercise, the deep reflection, the insertion of thought into the underground wefts of experience and the teaching performance, the learning and knowledge stemming out therein, the necessary distancing for the objectification of reality, and so forth. It means that systematization can take various forms, but its essence lies in its capacity to order and reconstruct the lived process, to critically interpret it, to extract lessons learned and share them with the professional community.

Systematization grants an own status to those who carry out practice and, in the Gramscian way, turns them into intellectuals going beyond a common sense and manage to make their own elaboration, avoiding a object/subject split and through the path of subjectivation/objectivation turns these actors into providers of knowledge, returning the human integrality (theoretical-practical) to their lives". [4] (Apud. p. 56). 
In other words, the systematization of experiences allows the empowerment and self-development of educational leaders who practice it, becoming epistemological subjects from their own practice and transformation, as part of the ever-lasting dynamic between theory and practice, between the internal and the external, between reality and its abstraction-generalization.

In short, the systematization of experiences is considered a valuable method of scientific performance because: it provides the knowledge of practice but transcending it; it reconstructs the historical practice to interpret it and obtain knowledge; it values the subjects of the experience; it appropriates the meanings of the experience and not only its meanings; it evaluates results from a constructive criticism; it is complemented with research and the production of new knowledge [14].

\section{Analysis of the Results of the First Experience: From Confusion to Collaborative and Developmental Work in the Discipline of Didactics: An Exercise in the Bachelor's Degree in Pedagogy at the University of Uberaba (UNIUBE), Brazil}

Context and background: The University of Uberaba (UNIUBE), Brazil (hereinafter the University, or the Institution) has a solid infrastructure of Information and Communication Technologies (ICT), with its own virtual environment and efficient support in this field. It has won a space in Distance Education (DE), with approximately $45 \%$ of its enrollment under this modality, in more than 30 centers spread in almost all Brazilian states. The University has approximately 30,000 students.

As of 16 March 2020, the Rector's Office, managers, and professors, with the support of the technical staff, implemented an emergency plan for the massive changeover of faceto-face courses to the remote teaching modality, due to the imminence of the COVID-19 pandemic. From that moment on, tutorials, online training courses and e-books were implemented, explaining various tools for online training, all for the urgent professor's training formerly engaged in face-to-face courses. A 24/7 support was implemented to clarify professors' doubts. Several digital libraries were also made available to teachers, as well as books and guides developed for the EaD courses. Google Meet was institutionally assigned as the main platform for remote teaching, available together with a robust G-Suite, with all the means for online teaching. Thanks to this, to the commitment of managers, technicians, and professors, in about two weeks, the institution was able to move $100 \%$ of its face-to-face courses to the remote mode. The University did not close and ended its first semester in July 2020, facing enormous challenges, many mishaps and many acquired experiences.

The biggest challenge was probably the speed with which these challenges had to be met, with little time for rest and reflection. From March to July 2020 there was where a period of enriched learning and professional transformation for the teacher-narrator of this experience story. The unexpected impact of the COVID-19 pandemic led us to mobilize responsibility, values, and sensitivity.

Once faced with remote teaching, the normal difficulties of technological communication emerged, such as noise, disconnections, lack of skills to manage digital means, lack of secure connection and lack of smartphones, laptops, and tablets for many students, among other difficulties that began to complicate the teaching procedure. In addition, some students were unemployed and most of them were struggling to survive. Some had to work at night, for example, or arrived late to class because they were engaged in other jobs. These circumstances also gave rise to the notion of asynchronous work, together with the maintenance of a synchronous schedule, to solve these difficulties. In addition to this, there was a collective stress caused by the pandemic, the frequent infection of students' relatives and their hospitalizations, as well as the infection of a student in the class with COVID-19. As an obstacle to learning, students had difficulties in understanding and producing scientific texts, solving study tasks, appropriating scientific concepts of discipline, and developing professional skills. How to provide them with the levels of support they needed through remote teaching? How to make better didactic use of digital technologies to organize a collaborative and developmental work? How to support individual and 
group learning and intellectual-professional development needs? These were questions that concerned the professor and led him to search for online pedagogical solutions. Fortunately, the Vice-Rector's Office for Graduate Studies had created courses and ways of support that helped professors to overcome this quickly. The truth is that, in July 2020, after the first semester, the professor of the Didactics of the bachelor's degree in Pedagogy at the University of Uberaba (UNIUBE) had a clear vision of online work methodology that he could use with his students in the second semester of 2020, overcoming at least most of the difficulties created in this context.

While the professor is engaged in his didactic research with the theory of developmental and collaborative learning (Section 2), the theoretical framework of the experience was evident for him from the beginning. So, this theory indicated the creation and development of learning activities, as well as the selection of the digital resources necessary for the work with each unit. This was planned in the subject's chronogram, in the stage prior to the beginning of the semester in which the experience was developed. Theory and methodology were evident; the challenge was to implement the strategy in remote teaching.

Participants: The experience described below was developed in the second semester of 2020, from August through December of that year. It was implemented along with 4th semester students involved in the bachelor's degree in Pedagogy at the University of Uberaba (UNIUBE), Brazil, in the nighttime classroom teaching modality. At the beginning of the semester, the group enrolled 35 students; their average age was 23 years; $95 \%$ of them were working, better say, they worked during the day and studied at night. Of the initial enrollment, 5 students dropped out due to several reasons, accounting for a $14.2 \%$ dropout rate. The subject was scheduled for $80 \mathrm{~h}$, four hours a week for 20 weeks. Two hours (100 min each) on Monday and two further hours on Wednesday in the evening.

Didactics: Once the second semester began, in August 2020, with the aforementioned group, a teaching strategy was implemented which, for each unit or subject, endured: (1) a detailed learning guide, with topics, objectives, activities to be implemented, book reference and ways for evaluation; (2) a unit study guiding class, including learning aids, strategies and activities, so that the students would make up a clear mental plan of what was required from them in that topic; (3) on average two classes (100 min each) of theoretical debate of the literature and/or recorded classrooms as learning aids; (4) seven virtual classrooms were set up, in the form of Google Drive papers, with teams of no more than four female students per classroom. The link to virtual classrooms was shared only with the female students in each classroom. In each of them, the coordinator and the rapporteur were selected and in the middle of the semester, these responsibilities were shared among them. In each unit, an article or book chapter and a video lecture on the topic by a professor from another major university were endured, so that the female students would count on information in no less than two media.

From the main Google Meet room, the professor could join each of the virtual classrooms, check the activity in progress, help in writing and/or coping with the assignments, write guidelines for the group and provide several levels of assistance, without coping with tasks under the female students' control. In turn, the female students could alternate between the main room and the team rooms. In the main room, guidance was given, doubts were clarified, questions were asked, and the results of the tasks solved by each team were discussed.

The teams' rooms remained open for asynchronous access by the participants at any time. This made it easier for those who had difficulties to be in the synchronous moment to do so at any other time. Each female student in the room had to choose a color for her note taking, so that it was easy for the professor to know what the contributions were of each one in the solution of the study assignment being carried out and leave suggestions through notes.

This form of collaborative and developmental work allowed that, with the professor's pedagogical support and that of the female students among themselves, important study tasks were solved such as: (a) different types of summaries of book chapters or articles, 
(b) formulation and gradual derivation of teaching goals, (c) substantiating the use of this or that teaching method or strategy for certain content in primary education, (d) planning learning assessment tools (tests, with themes, objectives, questions and checking and marks keys), (e) elaborating the didactic system (planning) of complete teaching units, in different elementary school subjects, (f) conducting online exams with the assistance of Google Forms aids.

Results: In this section we present barely two fragments of collaborative work elaborated by the participating female students. We have decided to bring the solution of a study assignment (In developmental learning theory, the study assignment is considered the core of study assignment. The study assignment is the specific activity that is formed at school, under the scientific guidance of well-trained professors in this perspective. The task is the cell of this process because it contains all the essential links and relationships that determine the study assignment information [20].) of lower complexity and another of higher demands, which by comparison allows us to observe the qualitative leap in learning and the development of skills attained by the female students. These activities were aimed at solving complex tasks, seeking to work in the Vigotski Zone of Proximal Development (1997).

\subsection{An Example of a Summary on the Concept of Didactics Made by the Female Students from the Virtual Classroom 1}

In the examples cited in this and subsequent subtitles, for reasons of identity preservation, the names of the students are omitted. The wording of the students has been retouched to preserve the academic language, without changing the authors' ideas.

As explained before, at the beginning of the semester, an overall difficulty was related to textual comprehension and production. Aware of this, the professor had to provide time and effort to this question by means of revisions, discussions, and demonstrations on how to improve a written text, adjusted to academic standards. A guideline was settled by stating that any well-done study necessarily ends up with writing, for which it is necessary to exercise and master the codes of this form of expression. It became clear that the mastery of writing is an indispensable professional teaching skill. Let us look at an example in Table 1.

Table 1. Summary of content by a female student.

It is also worth mentioning the conception of another science being a part of Pedagogy: Didactics.
It analyzes the ways, conditions, and foundations of the teaching and learning process. Therefore,
it focuses on the relationship between professors and their students as they mediate knowledge.
Moreover, it selects content and methods based on teaching goals and is linked to subject-specific
methodologies, which are responsible for determining the content and methods of each specific
subject (mathematics, Portuguese, history). In view of all the facts mentioned, it is undeniable
that there is a great and indispensable relationship between these terms, since one provides the
basis, explanations, and clarifications of the other. Furthermore, one investigates the determining
processes of the other, for example, Pedagogy investigates Education and Didactics, which are the
basis of Pedagogy. All this with a single objective in mind: to transmit knowledge to the subjects
that make up society. (Fontes: Libâneo, José Carlos. Didática. $28^{a}$. Ed. 2003 Aula em vídeo: Ser
professor hoje, Prof. Celso Antúnes, 2010). Source: The professor's own records.

This excerpt shows how female students were able to gather information from two different sources, in different media, to obtain a summary of the concept of Didactics, with excellent textual coherence and cohesion. It is evident that the female students surpassed themselves and developed important professional and communicative competences in this regard. One of the teaching requirements to achieve this and other goals was that each group had to present their outcome to the whole class, once finished. This generated a friendly competition among students, so that each room preserved its results until the moment of presenting them in plenary. This result, as well as the following one, shows the effectiveness of online collaborative and developmental work, according to the learning 
theory that serves as a basis, already described in 2, and the methodology applied in the experience, observed in 3 .

\subsection{Fragment of Planning a Teaching Unit, Developed by Female Students of Virtual Classroom 3}

The most complex learning task carried out along with this experience was the planning of the didactic system of a unit or subject matter of an elementary school subject by the female students. Each class or group was free to choose the subject of their preference. Some worked with Mathematics, others with Natural Sciences, others with Portuguese Language, Arts, and so on. The task was a great challenge because it integrated almost all the theoretical-practical knowledge acquired during the semester. As the units may have many hours/classes, each group elaborated on average a sub-unit of between three and four 50-min classes. Three 100-min classes were devoted to this work, with the professor's support in each classroom, encouraging discussion and collaboration among students. It was necessary to conceptualize categories such as theme, goals, contents, methods, evaluation, and their practical elaboration, which required the use of many professional and intellectual skills. Due to space constraints, the following example in Table 2 shows only one class of a larger didactic system.

This example of teaching planning shows how female students learned to plan their classes with all the necessary didactic aids. As it is known, for professors being trained, learning to plan teaching in a scientific way is significant. This example shows the elaboration skills acquired by the female students and the application of didactic knowledge to such an important teaching function, all carried out through virtual classrooms in remote teaching. This means that although it is true that remote teaching does not solve all the problems of communication, affectivity, and interpersonal contact, quite necessary for the full development of personality, at least it is a viable alternative to solve the great learning challenges in times of social disasters such as pandemics, wars, natural catastrophes, etc.

Assessment of the experience. In an online collaborative work experience such as the one we present; it is important to begin with the students' evaluations. By actively and consciously participating in the work carried out, they were subjects and objects of their own transformation, so their opinions are considered as relevant as those of the teacher who conducted the exercise.

At the end of the semester, the female students were asked to voluntarily write down their individual testimonies about the work carried out during the semester. Out of the 30 students, 24 sent their statements, in other words, $80 \%$ of the group. Due to space constraints, we will quote only two of them here, in the Table 3.

Student A, at the beginning of the semester, was diagnosed with a low academic performance, with difficulties in understanding scientific texts and in textual construction. The testimony of this female student is striking for her clear understanding of what happened during the COVID-19 pandemic. She shows that she learned to write correctly and that her thinking developed visibly. She discovered the potential of technological aids for her training as a pedagogue. At the same time, it shows us that when the teachertrainer uses these digital means, the future teachers add technology into their pedagogical work; better say, they naturally integrate the didactic functionalities of ICTs into their pedagogical knowledge. 
Table 2. Excerpt from the planning of a teaching unit.

\section{IDENTIFICATION}

School: Paths of knowledge Component/Section: Geography/The subject and its place in the world.

Grade: 2nd year of elementary school Date(s): 03/2021

Professor(s): [students' names are omitted to preserve their identity].

GENERAL METHODOLOGICAL DEFINITIONS

Unit title: The Means of Transportation

General goal: Compare different means of transportation, indicating their role in connecting places, as well as discussing the risks to life and the environment and their responsible use.

Main Method: Joint elaboration, demonstration, and group work.

Evaluation: Written test with objective and dissertation questions.

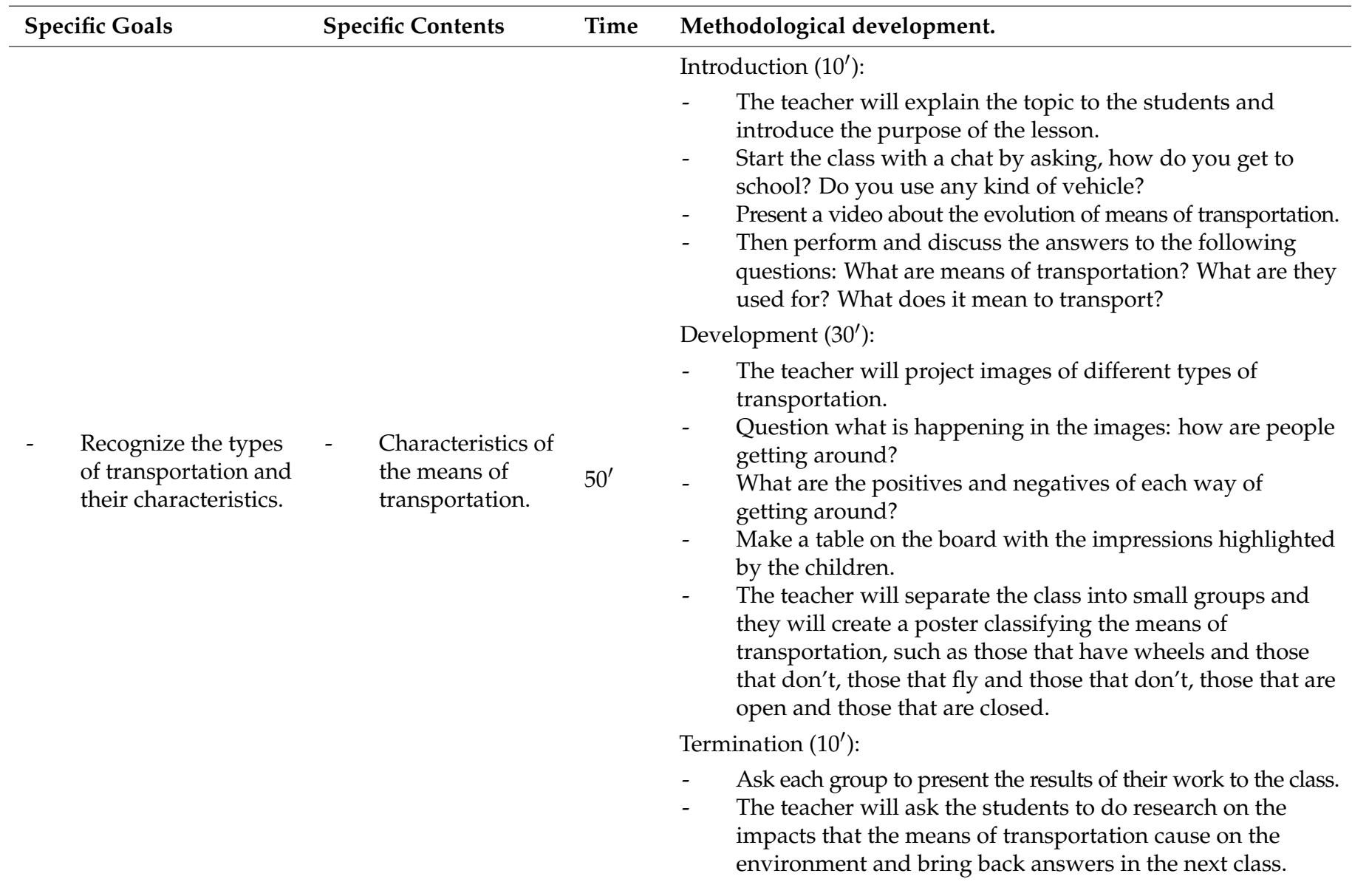

Source: Professor's own records.

Student B is a high achiever, working as an English teacher for young children. She is skilled in the use of digital technologies and usually assisted the professor and her colleagues. Her testimony shows assertiveness in communication, intellectual development, and her commitment to teaching through remote teaching. No less important is her clear awareness of the relevance of technologies for the development of the teaching function in the post-pandemic period.

Final considerations. The testimonies of these female students are samples of the balance that can be drawn from this systematization of experience. On our part, there are some aspects that we consider significant to stand out. Firstly, this experience was possible thanks to the broad institutional and technological support of the University of Uberaba (UNIUBE), an institution that diligently and safely implemented the massive transition from face-to-face courses to the remote modality, sparing no effort in terms of technological support and preparation of the teaching staff to assume such a change. 
Secondly, the commitment and professional effort of teachers to assimilate changes, master the technology and move to a new teaching organization in a record time. Thirdly, the crisis described above led to a sharpening of the sensitivity of professors and students, increased solidarity, understanding of the other, and flexibility of teaching work in the new reality. This flexibility ranged from the abandonment of the old ways of presentiality, with respect to presence in class, extreme demands in evaluation, to the combination of synchronous and asynchronous moments of teaching. It is a reality that, in this case, given the minimum material conditions, students and professors allowed a restructuring of teaching in a new context, with alternative means until then. This is one of the great lessons to be learned from this experience.

Table 3. Feedback from students participating in the experience.

\begin{tabular}{l} 
Students' Testimonials \\
\hline Student A: Testimonials from the students: "Remote learning came suddenly. The way we \\
worked in the Didactics course with Prof. Orlando not only changed our understanding of the \\
new learning situation; it helped us to be more careful in understanding the texts, to be more \\
careful when studying and summarizing, it made us more responsible with the subject contents \\
and with solving the study assignments. The online collaborative work made us more responsible \\
with our schedules because we were faced with a new way of conducting classes, more flexible \\
and dynamic than in the face-to-face modality. [ . . . ] With the activities organized in the virtual \\
classrooms I learned a lot. I learned didactic theory, teaching methods and means, how to \\
elaborate school evaluation instruments, how to elaborate objectives and sequence school \\
contents, how to make lesson plans of complete units, with all the didactic requirements. \\
Collaborative work through remote teaching has facilitated this learning process, overcoming the \\
difficulties imposed by the COVID-19 pandemic. Didactics is an especially important subject for \\
the education of educators; it is an indispensable theoretical and practical tool for the profession. \\
In this course we have lived with technology 4.0 in a pleasurable way. This technology not only \\
helped us in our studies, but also prevented us from failing this school year. With its help, we \\
studied normally and provided unity between students and teachers in a very delicate year."
\end{tabular}

Student B: “In the Didactics subject, collaborative work was organized by means of virtual classrooms. This way of preparing the teaching work was fundamental for the meaningful learning of the contents. Working together in small groups and the open dialogue with the teacher allowed us to deepen our knowledge of theory and practice, especially while organizing and researching group tasks. Furthermore, the communication with the professor of the subject was indispensable, since there was an opening for dialogue and cooperation, allowing the students to remove our doubts and build our intellectual skills about the profession. It was extremely rewarding to learn the content of didactics in theory and in practice, even if it was online."

Source: Professor's own records.

The experience developed in the subject of Didactics of the bachelor's degree in Pedagogy (University of Uberaba-Brazil) has allowed to verify that the organization of teaching, through virtual rooms in remote teaching, allows students to perform a collaborative and developmental work in the solution of complex study assignments, always supported by the professor and with the flexibility to combine synchronous and asynchronous moments of learning. The students' results are scientific evidence of this. As explained in the theoretical and methodological basis $(2 ; 3)$, experience shows that in this sort of work, female students are empowered, become subjects of their self-transformation, develop themselves and appropriate the teacher's online work methods, which is supposed to have an impact on their future professional performance.

\section{Analysis of the Results of the Second Experience: Learning Based on Autonomous Work Skills: Practice Evaluated at the Technical University of Manabí, Ecuador}

Context and conditions under which the study was carried out. The Technical University of Manabí is an Ecuadorian public institution that assumes a constructivist educational model based on its social current and the historical-cultural approach of Vigotsky. Its model is based on goals, policies and strategies leading to change and contribute efficiently to performance [21]. 
The face-to-face mode is the one with the longest tradition since its creation in 1952, so it is a challenge to assume professors' training in virtual conditions; although there were already some careers in on-line mode, but recently established. It is assumed then that neither students nor professors were able to face remote training.

The implemented modality was that of asynchronous virtuality, taking into consideration the premise of offering an opportunity for all students to access their training based on their economic possibilities. Classes, videoconferences, bibliographic aids and learning evaluation were inserted into UTM's virtual platform, while other platforms such as YouTube and Google Drive were also used to store video classes and bibliographic materials.

For the follow-up of individual needs, synchronous and asynchronous tutoring sessions were conducted through WhatsApp, Facebook, Cisco web and Google Meet platforms, among others. The sessions were carried out as a reinforcement and assistance means in the autonomous activities if there existed linking conditions and were recorded for those who could not attend in real time.

The students with whom we worked under the conditions of asynchronous virtuality came mostly from the poorest sectors of the province of Manabí, structured in 22 mostly rural cantons; in addition, it included students from other provinces that due to lack of career or vacancies in their province move out to where they could find them.

At the beginning of the lockdowns in Ecuador, in March 2020, a survey of data collection was implemented for the Early Childhood Education career, which showed that at least $87.6 \%$ of the students had some means of connection with their professor and with the content of subjects; $76.3 \%$ had internet connection or some sort of access; while $14.5 \%$ had to go to public internet centers, despite the pandemic conditions.

The process has not only been difficult due to the conditions of access, but also to the economic and family health situation experienced by the students, who did not always have enough money to pay for Internet and sometimes the whole family was infected by COVID-19, and many of them died. Within this framework, the study was carried out, which shows the results on the incorporation of autonomous work skills by the students of the Early Childhood Education career during the academic periods of May-October 2020 and November 2020 to March 2021.

The skills of autonomous work; a pillar for the professional development of the student teacher. Sources state [22] that a student's success is shown in the level of self-confidence. An important component that influences these expectations is how students evaluate their own skills to learn and grow up as human beings. Training and skill assessment are not always present on the professors' agendas; however, it is what is mostly demanded by workplaces regarding university graduates [22].

Researchers in the field [23] propose 10 skills for the future workforce: "Sensemaking", among them, critical thinking; social intelligence; innovation and adaptive thinking; intercultural skills; computational thinking; digital literacy; multidisciplinary; design thinking; management knowledge and virtual collaboration.

Several authors [24-27], state that students' achievements depend to a great extent on the incorporation and mastery of autonomous work skills, which allow learners to make decisions later and become strengthened throughout life. These personal skills are adjusted to work, student, or personal contexts, but they must be under guidance from school, developed in school and then applied in specific situations.

Assessment of results. The experience was based on systematizing the learning results, expressed in the development of autonomous work skills, achieved by the 186 students enrolled in the subject Academic and Scientific Writing, during the period May-October 2020 and the 203 students along November 2020-March 2021. The general method used was the systematization of experiences and the application of digital semi-structured interviews using Google Form and Google Meet.

In the case of the systematization of experience, the learning results are expressed in autonomous work skills defined based on the criteria of [23-27], in that in this case, 
the teacher recorded the information from the class evaluations and the final exam. The selected sample was intentional, coinciding with the student population led by the teacher.

The information was collected based on the student's evaluation of achievements in four stages, coinciding with the groups of autonomous work skills worked on: identification of information sources; processing of information and learning; application of what has been learned; and communication of what has been learned.

The skills were assessed in a comprehensive manner, since they make up a process that, if not completed, cannot be fully developed in the learner; however, the results are presented by stages, coinciding with the logic that should prevail along with its acquisition.

The interview was validated following the steps of, literature review, concept exploration, list of dimensions and items. At this stage, the dimensions and indicators shown in the study were determined based on the criteria of [23-27].

Subsequently, the arbitrators were selected, professors from the universities of the coastal region of Ecuador were invited, summoned through social networks and email, a total of 234 participated. Then, the online test and retest were applied as a validation method of the instrument with a frequency of 15 days between them. The responses issued were subjected to the Kendall correlation coefficient, obtaining a margin of error of 0.09 and a probability of success of 0.91 for the teas; in the case of rates, the margin of error was 0.07 with a probability of success of 0.93 . The application of the method allowed to obtain a positive correlation of 0.90 , which indicates a very high value and reliability in the instrument.

To verify the internal reliability of the instrument, the Reproductivity Coefficient $(\mathrm{Cr})$ was applied, which is expressed in the relationship between the number of errors in the questionnaire and the total number of responses, being a value that ranges between 0 and 1 . When applying the test and the rates, a Cr of 0.93 and a $\mathrm{Cr}$ of 0.92 , respectively, were obtained, values that are considered very high and determine the internal consistency of the instrument.

Stage 1. Information source identification skills.

- Identification of sources of useful and reliable information for the content being learned.

- Obtaining and referencing source as such.

- Quick source readout.

- Selection of the content to be studied.

One of the systematized aspects was the student's criterion on the experience of developing skills to work autonomously during the lockdown period. Table 4 shows the evaluation of the stage regarding the identification of information sources.

Table 4. Level of development of internal information identification skills.

\begin{tabular}{|c|c|c|c|c|}
\hline Skill Assessed & $\begin{array}{l}\text { OAP } \\
\text { May.-Oct. } \\
2020\end{array}$ & $\begin{array}{l}\text { OAP } \\
\text { Nov. 2020- } \\
\text { Mar. 2021 }\end{array}$ & $\begin{array}{l}\text { Average } \\
\quad \%\end{array}$ & $\begin{array}{c}\text { Transformations Observed as a Result of the Skill } \\
\text { Assessment Process }\end{array}$ \\
\hline $\begin{array}{l}\text { Identification of useful } \\
\text { and reliable sources for } \\
\text { your subject matter }\end{array}$ & 8.3 & 8.7 & 8.5 & \multirow{5}{*}{$\begin{array}{l}\text { From the point of view of achievement, a discrete growth in } \\
\text { the acquisition of the skill is visualized, although it is important } \\
\text { to take into consideration the short, systematized time. In spite } \\
\text { of this, the students' understanding of the role played by the } \\
\text { skill and free time in their training has been observed. } \\
\text { The students also understood the links between the source of } \\
\text { information and the validity of the content, as well as the } \\
\text { importance of extracting a general idea and a deep idea from } \\
\text { the source consulted for the achievement of learning. }\end{array}$} \\
\hline $\begin{array}{l}\text { Obtaining and } \\
\text { referencing this source }\end{array}$ & 8.2 & 8.5 & 8.4 & \\
\hline Quick source readout & 7.9 & 9.3 & 8.6 & \\
\hline $\begin{array}{l}\text { Selection of the content } \\
\text { to be studied }\end{array}$ & 6.8 & 7.6 & 7.2 & \\
\hline Total & 31.2 & 34.1 & 32.7 & \\
\hline
\end{tabular}

Source: Survey, interview, and systematization of practice. Note: OAP = Ordinary Academic Period.

The table shows the behavior of the information identifying skill in its procedural evolution, with the selection of content to be studied being in less development, since the student generally gathers information from various sources, not always reliable due to 
their content, which sometimes may cause him to delay his task delivery or do it without the required quality due to the lack of connection of these two skills.

One interesting feature found is the progress attained by students in terms of their quick reading skill from one OAP to another. There is a coincidence that this quick look at the material is a strategy to identify the text value in consultation and determine their choice or not and their subsequent in-depth reading, as shown in the Table 5.

Table 5. Students' felt experiences.

Criteria expressed by randomly selected students from the interview conducted by Cisco Web.

EEPAO M-O 20: “In my opinion, the most complex thing was to achieve the connection between the selection of the content to be studied and the sources of information, since these are quickly identified without considering what is structured in the activity.EEPAO N-M 20-21: "The most significant aspect of this form of teaching for me is the freedom and the protagonist experienced to create our own learning, and to be able to exchange with other students and the teacher himself both in its construction and evaluation".EEPAO N-M 20-21: "Benefits and opportunity of technologies, including social networks for training, being able to bring the university to the home, adjusting the fulfillment of tasks to the schedules established by the university, but also to the conditions and times available to me, in my case I combine study with work and sometimes I searched from my phone for a video or a material for my learning at work, which I did not do before."

\section{Evaluation conclusion}

The most significant aspect of this stage is linked to the need to establish the links between first, the source I need and its content; second, the time I must spend or need to spend to get a general idea as quickly as possible about the chosen source. In this sense, the student was able to understand the need to choose quality material for learning and its subsequent analysis and reading for learning.

Source: Cisco Web Survey; Note: EEPAO M-O 20 Student interviewed in the Ordinary Academic Period May-October 2020. EEPAO N-M 20-21 Student interviewed in the Regular Academic Period November 2020March 2021.

Stage 2. Information processing and learning stage skills.

- In-depth source reading.

- Note taking and charting.

- Modeling.

- New reading.

- Understanding and rewriting of what has been learned.

This skill evaluation made it possible to understand the need to work harder in terms of their training, since it has been less developed than the skills of stage 1. The Figure 1 shows a summary of the obtained results.

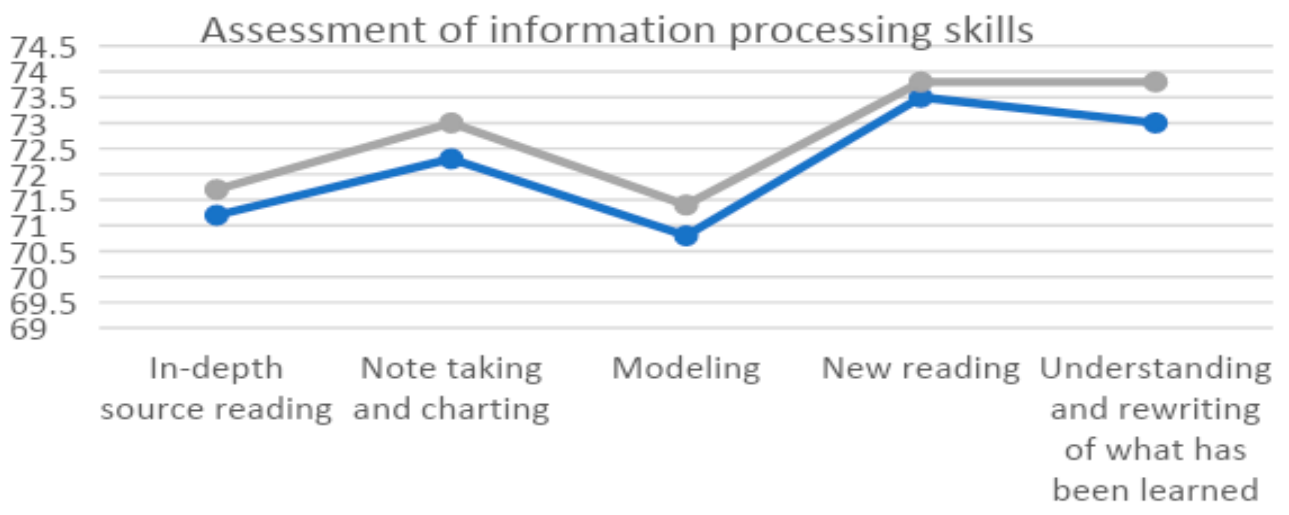

OAP May.-Oct. 2020 OAP Nov. 2020-Mar. 2021

Figure 1. Behavior of the information processing skill. Source: Cisco Web Survey. 
At this stage, the most significant aspect is the student's understanding of the need to strengthen this skill, denoting this is the one they need to work on better; they consider that the bibliographic material readings are not carried out with the required carefulness, it is difficult for them to fit learning at a mental and graphic level on a document. They also consider that, although to a lesser extent, the processes of understanding and rewriting of what they have learned require much attention, since on many occasions they do not acquire a good result.

The figure shows a low percentage of training regarding this skill; however, is a determining factor for their development, since it allows strengthening logical thinking processes such as analysis, synthesis, abstraction, modeling and conclusions. A clearly marked deficiency has been observed in modeling, as an intermediate skill in terms of logic at this stage of development.

In an overall interpretation of this phenomenon, it is considered that the average values of skill requirement at this stage is $73.4 \%$, an issue to be addressed if taking into consideration the individual development stage status as a university student; it is necessary to work on it to achieve a sort of self-training to be aware of understanding of the theory and reality that allows him/her to make decisions and count on accurate answers in a real work scenario.

Stage 3. Learning application skills

- Note taking, organization of information, answer adjustment.

- Writing a summary and providing conclusions of what has been learned.

- New searches derived from the acquired learning motivation.

- Preparation of products derived from learning (models, graphs, summaries, papers, software, etc.).

Regarding the formation of learning application skills, a slight increase in students skill acquisition has been observed from one OAP to the other upcoming; however, along with the stage two skill, it is the one they have developed the least. Figure 2 presents a summary of collected results.

\section{Assessment of skills at the learning application stage}

Preparation of products derived from learning (models, graphs, summaries, papers, software, etc.).
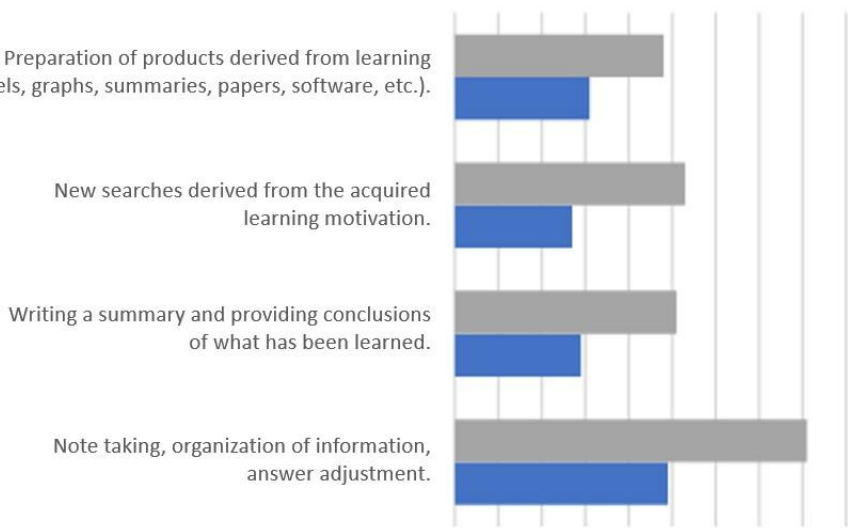

OAP May.-Oct. 2020

OAP Nov. 2020-Mar.2021

0102030405060708090

Figure 2. Acquisition Level of internal learning application skills. Source: Interview conducted by Google Form and Google Meet platforms.

The dialogue carried out with students to understand their assessment of the insertion and mastery of this skill showed up that they have deficiencies in notetaking; most students state shown videos for learning or bibliography readings do not lead them to the next stage of notetaking, although a significant growth of $32 \%$ was observed from one OAP to another.

The major issue at this stage lies in the fact that students still do not manage easily to grasp a summary of contents, the new searches stemming from their own motivation 
to learn and expand their information spectrum provided by their professor, as well as their own elaboration of products. In their statements, they express dissatisfaction while focusing on carrying out projects or tasks that do not result in interesting and profound source of learning.

Stage 4. Learning communication skills.

- Presentation of results and achievements.

- Oral communications: presentations, any others.

- Written communications: essays, projects, reports, summaries, final subject papers, individual works.

- Power point presentations, educational videos, or any other aid to support communication.

- Transformation of mental modeling into graphical outputs (graphs, concept maps, logic diagrams, diagrams, mock-ups, etc.)

This stage skills are better handled by students; they ensure that in one way or another during their career they have presented projects and tasks through power point presentations, videos, concept maps, among others; however, they accept that most of them derive from reproductive tasks that almost never lead to application learning. Table 6 shows the summarized results of what was systematized for this stage.

In our opinion, this stage of communication skills training is the best handled by students, although, as evidenced, many have been key players in its implementation, but without a conscious growth or a deep learning derived from the construction and presentation of results. They point out that many make a sort of preparation before joining class, apply learning by heart and the group does not take part in a comprehensive and equitable presentation.

However, the satisfaction of what has been achieved during these two academic periods is that more than $80 \%$ have understood the logical process to reach a truthful and quality-based learning, they acknowledge the need to focus on understanding the logical process of elaboration of auxiliary aids for the oral or written communication of their evaluative works, an aspect that is generally not included in university teaching and learning processes.

In general, the systematized experience at the Technical University of Manabí, although implemented in a particular context, can be seen as similar to others carried out in other countries in the region. The results of this systematization are part of a project being worked on for three years at the institution and become the basis for establishing new strategies to improve student performance in the development of autonomous work skills.

As a summary, Figure 3 shows the behavior of the development level attained by students in their four training stags in autonomous work skills once they have completed their second academic period in the asynchronous virtual modality.

Final considerations for this experience. The systematization carried out on the insertion and knowledge levels of the individual work skills allowed to understand the way students learn and their vision in terms of the learning process. Taking into consideration the aspects referred by students and what was systematized by the professor, it can be concluded that the individual work skills are insufficiently addressed by the teaching staff, thus still focusing on content learning.

Among the skills that require further reinforcement for students, there are those related to applying what they have learned in new real situations, since only $10.9 \%$ of the sample manages this, while $21.5 \%$ can process the information correctly after interacting with the source. Both intermediate skills are fundamental for the insertion of significant and lasting learning since they motivate the learner's logical thinking. 
Table 6. Students' criteria and considerations on the communication of their learning.

\begin{tabular}{|c|c|c|c|c|}
\hline & & $\begin{array}{c}\text { OAP } \\
\text { May.-Oct. } \\
2020\end{array}$ & $\begin{array}{cl} & \text { OAP } \\
\text { Nov. } & 2020-M a r . \\
2021\end{array}$ & Students' Considerations \\
\hline $\begin{array}{l}\text { Presentation } \\
\text { of results }\end{array}$ & $\begin{array}{l}\text { Oral and } \\
\text { written } \\
\text { communication }\end{array}$ & 85.7 & 89.4 & $\begin{array}{l}\text { EEPAO M-O 20: "In most of the subjects, group expositions } \\
\text { are presented as a form of evaluation". } \\
\text { EEPAO N-M 20-21: "Group expositions do not always } \\
\text { generate lasting or significant learning ( . . . I have noticed } \\
\text { that learning is achieved from the incorporation of the } \\
\text { communicative skill". }\end{array}$ \\
\hline $\begin{array}{l}\text { Explaining } \\
\text { and defending } \\
\text { learning }\end{array}$ & $\begin{array}{l}\text { Power point, } \\
\text { audiovisuals, } \\
\text { and others. }\end{array}$ & 84.2 & 88.6 & $\begin{array}{l}\text { EEPAO M-O 20: "I like to do power point, however, for the } \\
\text { presentations I get a little frustrated because not everyone } \\
\text { works on its elaboration". } \\
\text { EEPAO N-M 20-21: "I have worked in the elaboration of } \\
\text { videos to evaluate a class, however, I had not stopped to } \\
\text { understand that the skills I acquire in their elaboration are } \\
\text { also determinant for my development, beyond the final } \\
\text { product that is elaborated." }\end{array}$ \\
\hline
\end{tabular}

EEPAO M-O 20: "Yes, it is a lot of fun to elaborate concept maps for class assignments, sometimes they are difficult to make, but I like them a lot".

Graphics, concept maps, Abstract logic diagrams, description diagrams, models and others.
87.7 EEPAO N-M 20-21: "The elaboration of concept maps, graphs, logical schemes, are not taught much in class, one learns it in autonomy, however, as you have taught us, the processes and skills that I acquire during their confection, makes me reflect on the importance of learning the logic of a process, the incorporation of knowledge and skills at that stage, which is very different from the solution oriented activity, that makes me see learning from another perspective $(\ldots)^{\prime \prime}$

EEPAO M-O 20: "Not everyone always participates in the expositions with the same quality, in fact, many do not prepare to do so, however, the evaluation is almost always similar for everyone".

EEPAO N-M 20-21: "Yes teach, it is as you say, when the process of autonomous work is done from the search for information to the solution of the task one arrives with satisfaction to expose the acquired learning, because it is the fruit of sacrifice and conscious growth, I like this way that has shown us the way to study better and get better results"

Although the initial and final skills are relevant due to their role in initiating and closing a process, the processing and application skills are decisive, since they motivate the logic of thought, which is essential for learning. Analysis, summary, modeling, deduction, conclusion, among other skills, allow what students see, read, touch, or hear to become aware of; otherwise, they would be passing directly to the communication of information without a conscious learning process.

Although the extreme skills -initial and final- are the best mastered, they still need to be addressed. It is assumed that the influence of internet and other resources of the knowledge society has contributed to the development of students' communicative skills. For this reason, they can easily create infographics, videos, power point, essays, concept maps; however, they are not always aware of the logic of content and the understanding of processes for their own learning. Regarding the interaction with the source of information, the greatest difficulty lies in the selection of appropriate aids for their professional training. 


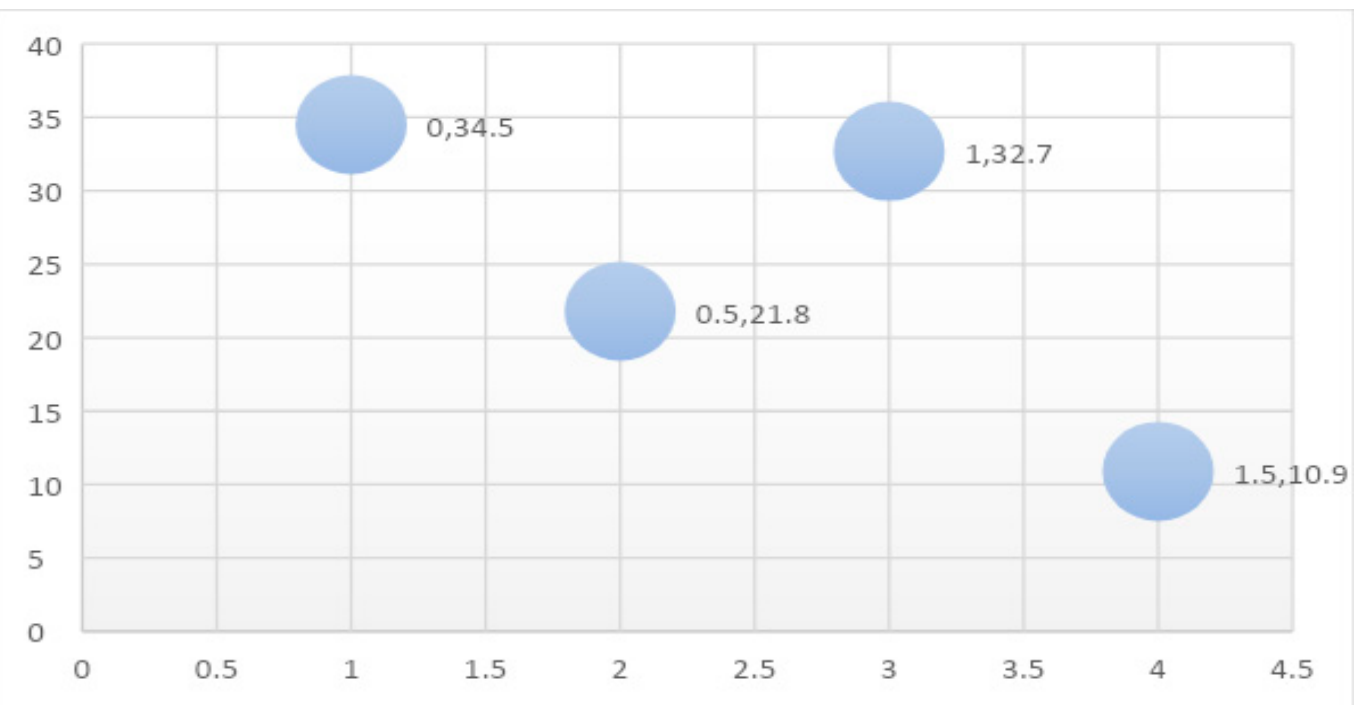

Figure 3. Level of incorporation of autonomous work skills. Source: Summary of the systematization attained from the survey considerations, the interviews, and the observations.

The transformation achieved in students, although with minor positive leaps, is a starting point for the project undertaken, which longs for moving forward into the logic of the formation of autonomous work skills, as a basis for personal growth and the development of lasting learning. Progress has also been made in the students' understanding of learning significance based on the logic of formation stages for the autonomous work skills. This is relevant in circumstances where the need to learn virtually is a great challenge for students and professors.

6. Analysis of the Results of the Third Experience: The Scientific-Textual Construction in the Formative Experience of a Doctorate in Education in Peru: Valuations of Feedback as an Asynchronous Process

Context and Study from the experiential narrative. A doctor's training in education brings about a challenge and an ethical commitment to higher education institutions. The former brings about the implication of a formative background that, from school, would not necessarily have laid the foundations for the development of an increasingly complex and higher thinking. This is a challenging task for training institutions, beyond the Regular Basic Education (RBE) level, which would have to assume the liabilities of an unfulfilled formative process.

Peru is permanently lagging behind in terms of worldwide stats, such as those introduced by the Organization for Economic Cooperation and Development (OECD) regarding PISA tests and in others generated by the Latin American Laboratory for the Evaluation of Education Quality (LLECE in Spanish); all of them associated with text comprehension abilities, among other skills, which call for a repertoire of structural cognitive potentialities and increasingly stratified and complex levels of thinking.

This demands an analysis from various perspectives in research processes focused on textual construction and a willingness to be flexible in the face of the transdisciplinary condition required at a doctoral level $[28,29]$. A vision that certainly demands an openness of all players involved since, in the history of academic training, behaviorist practices would have prevailed in teaching spaces [30].

For the worldwide educational policies and the country, itself, doctoral training has a strategic character since it involves the strengthening of its intellectual capital. If we consider that a doctoral candidate in Education needs to examine the context reality through a factual and epistemic diagnosis, which allows him/her to propose possible reactions for further theoretical-practical contribution, the need for a profile that is directed to this purpose begins to emerge. One way to achieve this is to empower the training process 
with efficient programs, in which epistemic competencies are developed, quite evident in scientific productivity. However, Peru has not stood out precisely for this [30], leaving a large gap with respect to the standards of publication and indexing, and therefore the scientific construction of a text.

On the other hand, it should be noted that the ethical factor is affected when the productive purpose is superimposed on the ideal and formative purpose. This is often identifiable when the classroom is massified and this is considered a priority that defines success in terms of institutional economic support, but not necessarily in terms of quality in doctoral training. Even more today when most institutions had to close due to the COVID-19 pandemic.

However, there are exceptions, and this would be the case of the reality included in this study, San Ignacio de Loyola University, a private university acknowledged in the educational field for his devotion to offer self-managed and entrepreneurial professional training, as well as training programs aimed at educators from its alliances and connections with the Ministry of Education of Peru, including self-initiated projects. One of them is the recent doctoral program in Educational Sciences, which emerged in 2019.

After the risks of the COVID-19 and the closure of the on-site classrooms, the applications to this program did not stop, reaching a registration of 33 applicants, the amount to be dealt with this paper, and who were accepted to start their studies on a totally virtual basis in 2020. This would involve the second promotion of students, different from the first one, which would have been initiated in 2019, with 14 students and in a face-to-face mode prior to the pandemic.

However, the 33 students of the second promotion did not always remain in terms of quantity, even more so with the new situations generated by an uncertain and overwhelming "new normality". By the year 2021, at the end of the second period, 20 participants remained registered, who were surveyed through a mixed questionnaire, administered in Google Form, which included 29 questions in a semantic differential mode, with varied choices and one open question.

The questionnaire was sent through the institutional mail account, in which the research purpose was informed. The requirement of informed consent, which includes the student's free choice to complete the requested survey, was complied with. All 20 students accepted the free informed consent and agreed to answer the survey.

Initially, the formation of the group of students was quite a challenge. The students did not know each other and had no possibility of a face-to-face contact. These doctoral students came from various professional fields and different socioeconomic and cultural backgrounds. The common denominator among almost all of them was their job as professors. Most of them were higher education professors. Less than 10 of them were elementary school teachers.

Systematized and sustained experience. The process of scientific-textual construction that is part of this formative experience involved two consecutive periods. The subjects of National Education Issues and Global Education Issues were developed. Each period development covered 20 consecutive weeks, in other words. 40 weeks, as an opportunity to generate an academic proposal for each course and link it to the scientific-textual construction goal.

Thus, the shared experience shows two consecutive academic events, in which students were accompanied asynchronously through the CANVAS platform. The notion was based on that each student, on a weekly basis, generated a scientific-textual construction advance which the professor systematically reviewed, generating feedback on each advance until the end of the term and consequent product. The weekly forums represented opportunities for a steady formative and asynchronous feedback. It was possible to put course objective into the promotion of the scientific-textual productivity. In the various moments of academic development, there were up to 4 possibilities to produce scientific articles, individually, in pairs and/or in groups. 
Table 7 describes four products aligned with the purposes of each course and with the construction of scientific texts. Although each product had a different proposal regarding the kind of scientific article, a central structure and sequence of development was always requested. In this manner, evaluation criteria were established for the different types of produced articles. Adaptations could be realized from them, which permitted the students to examine their progress and partially self-evaluate, until the culmination of the generated product for each course and assigned pedagogic space.

Table 7. Subjects taught during the asynchronous accompaniment process to insert the scientific-textual construction competence.

\begin{tabular}{lllll}
\hline Cycle & Subject & N. $^{\circ}$ of Weeks & Requested Product & Description \\
\hline \multirow{2}{*}{ I cycle } & Global education & $1^{\circ}$ to $10^{\circ}$ weeks & Essay article (individual) & Documentary analysis of context documents. \\
& issues & $11^{\circ}$ to $20^{\circ}$ weeks & State of the art report (working groups) & Literature review \\
II cycle & National & $1^{\circ}$ to $10^{\circ}$ weeks & Empirical article in pairs & Interviews with 10 experts. \\
& educational issues & $11^{\circ}$ to $20^{\circ}$ weeks & Scientific article(Group article) & Comparative education (research report) \\
\hline
\end{tabular}

Source: Own analysis; Note: The two cycles articulated 4 opportunities for scientific productivity accompanied from the Canvas platform asynchronous space. A total of 40 consecutive weeks is registered.

Table 7 below specifies the content of the main evaluation criteria applicable to the various kinds of written articles. Based on them, adaptations could be made so that students could examine their progress and partially self-evaluate themselves, until the completion of the product generated for each subject and assigned pedagogical space.

The processes of constant revision sustain an assertion to what Gadamer calls "reflective dialogues" [28]. Evaluation then becomes a reflective process of awareness [29], which invites the participant to look at his or her achievements and pending improvement. Always guided and accompanied by the course professor. The aim is to promote an "autopoiesis", a state of permanent openness to change, to continuous improvement, to self-regulation in the construction of texts, while constituting and embracing an individual stand.

Once the evaluation criteria were pre-established, they were shared with the class and tested during the working weeks. The progress of the product involved 10 consecutive weeks of systematic and progressive self-review through virtual forums publications.

The process of scientific-textual construction. The asynchronous accompaniment was carried out based on scientific-textual construction strategies being a part of the professor's current research line. Generating principles of complex and transdisciplinary thinking are determined, which can be evidenced along the comprehension of taught learning in the course and in relation to a topic under the student's interest. The professor offered a detailed review of the progress made by each student and made remarks on feedback, from the first to the tenth week of sustained work.

The accompaniment provides the student with a guide for the development of his own process, which permitted him to identify his objective, his textual enunciative summary, and relation between the analyzed sources in the text. Always in the progressive and constant communicative and argumentative exercise.

It was a process of scientific-textual construction, in which the student was accompanied, inviting him/her to reflect before, during and after each performance. The "reflective dialogues" [31] were permanent based on asynchronous feedback. This challenge involved continuous reflective processes (self-reflection and inter-reflection), exercises of representation of configurations and their relationships, by way of inter, intra and transconnection of principles, key notions, concepts and scientific sources involved. Transdisciplinarity became a condition of complex thinking, sought to be generated in this practice of progressive textual construction.

To put this into practice, self-evaluation rubric criteria were established. A color was assigned to allow each student to identify his or her level of progress. Although there were pre-established criteria in the self-assessment rubrics, these were complemented with a color identification showing the significance of achievement levels with respect to this 
Transconnective or integrative capability that this practice seeks to foster. Table 8 shows these levels and the concepts that define this proposal.

Table 8. Transdisciplinary and complex levels of thinking.

\begin{tabular}{ll}
\hline $\begin{array}{l}\text { Levels of Advancement in Transconnection, } \\
\text { Transdisciplinary and Complex Thinking }\end{array}$ & Summary of Description \\
\hline $\begin{array}{l}\text { 4th level: Transconnective level of high complexity } \\
\text { (YELLOW) }\end{array}$ & $\begin{array}{l}\text { Capability for integrative synthesis among all the elements. Argumentative } \\
\text { configuration that integrates contents of support analysis. }\end{array}$ \\
\hline 3rd level: Complex intraconnective level (GREEN) & $\begin{array}{l}\text { Ability to establish logical relationships between elements. Configurations } \\
\text { of different levels (hierarchical, inclusive, contrasting, etc.) }\end{array}$ \\
\hline 2nd level: Interconnective level (LIGHT BLUE) & $\begin{array}{l}\text { Ability to establish direct correspondence relationships between elements. } \\
\text { Configurations that integrate different levels of sequential logic. }\end{array}$ \\
\hline 1st level: Level of connective projection (PINK) & $\begin{array}{l}\text { Ability to identify fundamental concepts with configurations related to a } \\
\text { central core base. }\end{array}$ \\
\hline
\end{tabular}

Source: Own analysis; Note: These levels were referential that were attributed at the different moments of the asynchronous accompaniment.

The axis of this transdisciplinary condition " $(\ldots)$ concerns, as the prefix "trans" indicates, which is in between disciplines, across disciplines and beyond all disciplines. Its purpose is the comprehension of the present world in which one of the imperatives is the unity of knowledge" [28] (Apud. p. 35). In terms of this guideline, the transdisciplinarity of textual construction defines levels of complexity that broaden perspectives and enable a change of perspective in scientific writing.

This transdisciplinary approach amalgamates new ways of building up a text. It is a matter of giving a priority to its essence rather than its form, without disregarding the norm contributions, while complementing certain processes of a heuristic and hermeneutic nature that give full consistency to the purpose of scientific communication [31]. To this effect, scientific production introduces processes identified by certain perspectives, such as theoretical methods [31].

Thus, by inserting the cognitive psychological perspective into the heuristic and hermeneutic processes of this epistemological vision, there comes up identified methods that directly contribute to the reflective exercise of textual construction. The analysis and synthesis require going deep into the review of the cognitive processes involved which allow students to question, elaborate and rework their meanings from the insertion of operations of contrast, induction, deduction, historical-logical sequence or even mapping. With all this, the aim is to arrange a speech having a greater argumentative solidity and sequence.

Representational mapping: an epistemic strategy of scientific-textual construction. When Ausubel proposed the meaningful learning, he was laying the foundations of complex thinking based on the subject's capability to integrate new knowledge with that already possessed. A sort of "anchoring" that ensures a "lifelong learning". This is a principle in the development of a competence that introduces levels of complexity and cognitive comprehension.

If it is evident that a process of scientific-textual construction is a potential activator of scientific knowledge, it is a condition of meaningful learning. However, the researcher and article writer not only learn, but also understands and shapes an onto-epistemic stance towards the subject matter reviewed.

Building the scientific text is a constant exercise of reviewing contextual and theoretical sources, reflective and comprehensive analysis, construction, and deconstruction, among others. Forging an epistemic position and translating it into the text is not a simple task; it requires rigorous practice, discipline, and continuity. It requires levels of representational synthesis that, from Asbell's theory, are highlighted by contributions such as Novak (Ausubel's follower), with concept maps, and Tony Buzán, with mental maps. 
Knowledge needs to be represented, showing its configurations, in a sort of relationship that may be hierarchical, interconnective, sequential, historical-temporal, inclusive, contrasting, among other possibilities. The concept of "representational maps" then arose, which were requested in the forums prior to writing. These were original and unique representations, in which each student showed how he/she was able to arrange concepts and provide meanings to them; amalgamating them with the knowledge already possessed, to offer a textual content with sense and congruence; but, above all, revealing a stand and a definition for all being analyzed.

Representational maps were presented together with the progress of texts, and revealed an evolution of thought, the organization of ideas and the synthesis of a textual proposal of interpretative level. They revealed statements that articulated constituent and evident elements on the text itself. Seeing a map meant seeing "the whole", just to see eventually what was shaped and embodied in the text. Then a relationship between this representational synthesis and the textual content and sequence could be established. Both were evolving in time and along the weeks of the article development. Generally, maps were requested up to the 5 th week of text construction, and as each part of the text sequence was developed.

Students could access to the platform forum, their texts, and their maps. The latter ranged from handmade works to the use of Power Point slides, Geogebra, Cmaptools, among other aids of their choice. The idea was to represent as well as possible what was to be depicted in the text; and that at a "simple glance" it would be understandable and then verifiable.

In this manner, the "representational maps" strategy constituted an opportunity for the students to organize and clarify their ideas in a systematic way. From the reflective spaces and the source analysis provided by the course, they reviewed topics that allowed them to define an analysis topic, pinpointed to initiate an exercise of problematization and argumentation.

The maps denote the configurations of the educational issue with a contextual and conceptual basis. The representations of knowledge are arranged, and the elements are dynamized, providing them a level of relationship, being later embodied in the text. The scientific-textual construction then becomes a process of great cognitive organization. It starts by focusing on the subject matter, in a certain context and with certain subjects. Processes of reflection, analysis and comprehension are applied to grant meanings and interpretations to the educational phenomenon. Epistemic dynamics of ontological, praxeological, epistemological and axiological basis are activated. All of them are a possibility of epistemic processing leading to forge a high-level formative process in the future doctors in Education.

Results and discussion. Along this experience, doctoral training turns out to be a challenge for the trainer and the companion. It is a matter of initiating a process of accompaniment favoring the development of textual integration capabilities, from the bases of complex and transdisciplinary thinking, but it is also a matter of achieving a disposition to the task of constant scientific productivity.

The students' sample, finally reduced to 20, did not stand out for having indexed publications. In addition to this, the purpose of forging competencies related to research and systematization of specialized scientific literature. These would have been starting points for scientific-textual construction, as they are basic players of the quality that a doctoral program should have [32].

On the other hand, it is significant that not all students would be educators from their basic training; being novel the educational theme approach and what it demands in terms of content and knowledge requirements.

The survey results applied to the students at the end of the second cycle, in April 2021, reveal the first signs of this assessment, which provides them with the process of asynchronous support and feedback for the construction of the scientific text. 
Considering the results, 14 of these students, representing $70 \%$ of the sample, it was estimated that they have a high level of knowledge and management in relation to when they began their training process. This is also shared absolutely by two of the 20 students. In general, the result denotes a high rate of value of what has been affirmed.

Along the same line of acknowledgement, by means of the students' testimonies, when asked the only open question of the questionnaire. Regarding this question, they were required to explain their highest evaluation in terms of the formative experience of the text scientific construction of the article. Among these evaluations, it is noteworthy that the level of progress in knowledge and management is evident from the formative process of feedback.

I consider that this formative process has helped me to clearly identify the structure of a scientific article that, without the professor's indication, would have been complicated to understand it, apply it and attain results.

[ED1]

The structure of a scientific article was guided during the training event, allowing students to understand what they had to do for each sequence of development. This student assures that this new knowledge was much better for him in terms of his own understanding and application, thanks to the fact that he had someone to guide him in this process.

However, the evaluations highlight much more than aspects related to the knowledge and handling of a scientific article structure. Already having the effective cut at the level of monitoring results, the data show in Figure 4, that one of the 20 students would already have two indexed publications as a product of this period, and that 5 of these students would have published at least one indexed article. This is relevant, considering the 40 weeks that the process lasted.

How many articles have you produced as a product of the course to date, but not yet published?

Count those produced individually and those produced with other classmates.
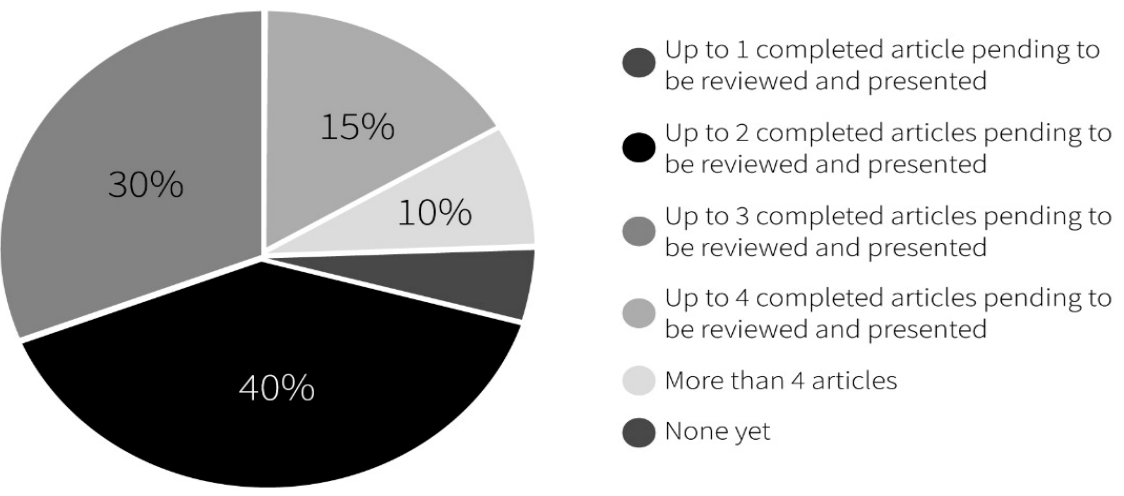

Figure 4. Results of publication achievements in indexed journals. Database Survey administered to 20 students of the II cycle doctoral program in Education through Google Form (April 2021).

However, scientific productivity is much more significant, with the results shown in Figure 5, when 19 of these students state indistinctly that they already have an article in progress, which has not yet been published, but which evidently would be the result of the acquired support. 
How many publications do you have as a result of this formative process since you started in the first cycle?

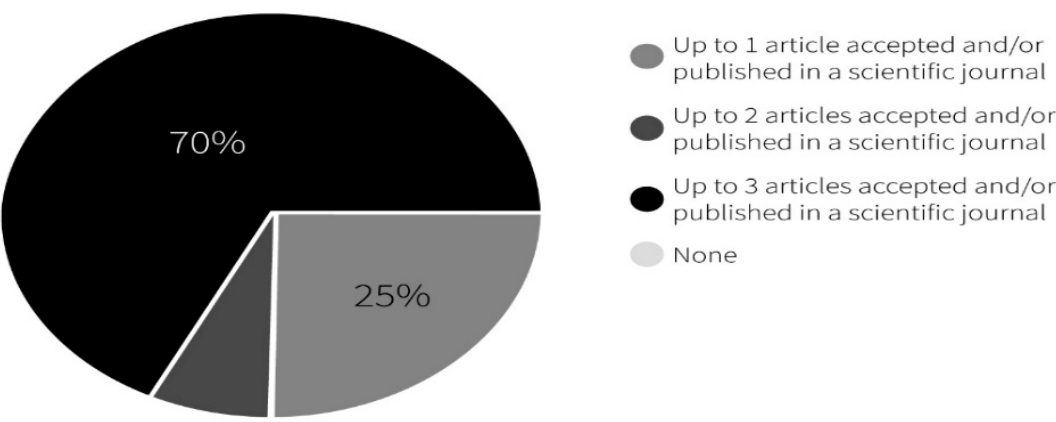

Figure 5. Results of the number of articles produced in indexed journals. Database Survey administered to 20 students of the II cycle of doctoral program in Education through Google Form (April 2021).

This result is important, since eight of these students (40\%) claim to have already published two articles, six of them with three articles, three of them with up to four articles and two of them with more than four articles. This last valuation exceeds the possibility of developing articles, which was four, and shows other possibilities generated from this learning process and the new knowledge and management acquired.

The students' awareness of their progress in this capacity and the evidence of scientific productivity generated from the accompaniment and sustained asynchronous feedback are highlighted. Thus, Figure 5 reflects this assessment in a more general way.

It is noticeable that 13 of the 20 students, in other words $65 \%$ of the sample, that accompaniment is a factor that determines the scientific-textual construction.

This is reaffirmed in some answers to the open question, in which they are asked to explain what they value most in this formative experience in terms of a scientific text construction, and all what it implies. These are answering that state common appreciations about the asynchronous accompaniment and realize the importance of some more singular aspects from their own expressed valuation.

What I value most is to pleasantly recognize the vocation of teachers, which is demonstrated in the constant accompaniment they give us, besides that, having learned to use techniques and tools throughout the whole process of scientific construction, I feel that as a professional and teacher I have greater capabilities to exercise in each field, an extra help both to other professionals and to my students.

[ED11]

The accompaniment and sustained feedback for the search of information, structure and reflective and hermeneutic processes that should be manifested in a scientific article to ensure its relevance and scientificity.

[ED18]

The I value most in this formative experience process is the sustained accompaniment and constant feedback (... ).

[ED4]

From their speech, evaluations of accompaniment emerge that highlight the teaching role as a constant accompaniment that has promoted reflective processes, flexibility, and hermeneutic exercise. All this would have led to a result of progress in the knowledge and management of scientific textual construction, as a learning achievement demonstrated in the scientific productivity reported by the students themselves.

In a Complementary way, it is noticeable that some of the evaluations express aspects more related to the development of epistemic thinking. There is a recognition of strategies 
linked to the elaboration of representational maps that help to check progress in terms of the capacity of analysis and synthesis, among other strategies, formulated in the surveyed students' comments.

My formative process for scientific-textual elaboration began with representational maps, which I consider vital in the process.

[ED7]

The incorporation of new methods of information processing and analysis are the basis for the possibility of applying to higher ranked journals. I take this experience with the expectation of achieving a publication in Scopus until reaching Q1 after the learning curve acquired.

[ED3]

What I value most of this formative experience of building a scientific text is the mastery and ability to teach us using multiple strategies for us to develop the competence of scientific textual production, which involves extensive research and reading.

[ED15]

The Methodology taught ( ... ) in different ways and with both we arrive at the construction of the scientific text. The hermeneutics in the contextual maps impacted me. The process of reflection, flexibility, and feedback to culminate the scientific text.

[ED5]

The evaluations would be confirming the contribution of asynchronous accompaniment as an experience that empowers ae future doctor in the development of an epistemic competence of scientific-textual construction, which necessarily requires sustainability over time.

The teaching task is defined as that of an "attractor" of this students "willingness to be accompanied and guided, understanding this learning experience as an opportunity for evolution in learning, turning this into a new potential and significant knowledge.

Final considerations. The formative experience in Peru shows asynchronous accompaniment as an effective means to develop processes of scientific-textual construction from a sustained and constant accompaniment. This promotes the possibility of scientific productivity and mainly the development of the capability for the comprehension and higher levels of cognition related to the complex and transdisciplinary thinking. Thus, feedback that promotes a reflective capability, permeability to the processes of textual construction and deconstruction and the hermeneutic exercise guided to create an awareness of strategies that can be productive for self-regulation and progress in learning. Representational maps and reflective dialogues are identified as a key element of this whole process and as dynamizing factors in the progress of the epistemic competence that needs to be forged in a doctor in Education.

\section{Conclusions}

With this article, the objective of relating three teaching experiences implemented during the COVID-19 pandemic has been fulfilled, aimed at developing the pedagogical knowledge of teachers in training, based on online teaching practice. These experiences are representative of the efforts made by thousands of professors and university students in Latin America to incorporate the use of digital technologies into the teaching-learning processes, as a means of transforming teaching practice. As has been shown, the public health, economic and educational crisis unleashed during the COVID-19 pandemic also brought with it the mobilization of creativity, sensitivity, and solidarity to face the problems of educational practice in the training of teachers, both at the undergraduate and postgraduate levels. 
The three experiences, although carried out in a parallel way over time, in different university contexts, are related to each other from aspects such as the following: (a) they are the result of part of the creative searches of teachers and students to maintain teacher training, through remote teaching, as a pedagogical alternative to the crisis caused by the COVID-19 pandemic in 2021; (b) the focus of the three experiences was placed on developer learning and collaborative work between teachers and students; (c) the results of the students are similar, which shows that there is no single methodology, nor a single way to enhance the learning and development of teachers in training; (d) the teacher-trainers were careful to record their experiences and relate them to the scientific community, which contributes to the systematization of the pedagogical knowledge of education professionals; (e) the experiences are linked by a superior global dialectic that surrounds the educational systems of the region.

At the same time, it is found that the contexts and the subjects participating in the experiences are different, but these differences are important because they teach that nothing surpasses the will and commitment to the training of students, in circumstances as adverse as those that created by the COVID-19 pandemic around the world. These experiences, each related in its context, are relevant because they show the potential of digital technologies to put into practice collaborative and developer learning; the training possibilities that the combination of synchronous and asynchronous moments must promote learning and comprehensive development of students; those students can also be motivated through remote teaching and engage in their development. Experiences show that in this modality they also empower themselves and develop autonomous learning skills, becoming subjects of their self-transformation. This is possible provided that correct educational use of digital technologies is made.

Author Contributions: O.F.A. wrote the introduction, the theoretical framework, the first experience and the conclusions of the manuscript. He posted the article on the MDPI platform and maintained communication with the journal's Editor and with the reviewers; P.M.Z. wrote the third experience, she had intense participation in the successive reviews that were made to the entire manuscript, as well as in the responses to the three reviewers; E.R.C. wrote the second experience, he also had intense participation in the successive reviews that were made to the entire manuscript, as well as in the responses to the three reviewers. All authors have read and agreed to the published version of the manuscript.

Funding: This research received no external funding.

Institutional Review Board Statement: Not applicable.

Informed Consent Statement: Not applicable.

Data Availability Statement: Not applicable.

Conflicts of Interest: The authors declare no conflict of interest.

\section{References}

1. Vigotski, L.S. Pensamiento y lenguaje. (Thought and language). In Obras Escogidas, 2nd ed.; Visor: Madrid, Spain, $1997 ;$ Volume 2.

2. Vigotski, L.S.; Luria, A.R. El Instrumento y el Signo en el Desarrollo del Niño; Fundación Infancia y Aprendizaje: Madrid, Spain, 2007.

3. Leontiev, A.N. Actividad, Conciencia y Personalidad; Pueblo y Educación: La Habana, Cuba, 1983.

4. Leontiev, A.N. Uma contribuição à teoria do desenvolvimento da psique infantil. In Linguagem, Desenvolvimento e Aprendizagem; Vigotski, L.S., Luria, A.R., Leontiev, A.N., Eds.; Ícone/Edusp: São Paulo, Brasil, 2010; pp. 59-83.

5. Galperin, P.Y. Sobre la formación de las imágenes sensoriales y de los conceptos. In La Formación de las Funciones Psicológicas Durante el Desarrollo del Niño, 2nd ed.; Quintanar Rojas, L., Ed.; Universidad Autónoma de Tlaxcala: Tlaxcala de Xicohténcatl, Mexico, 2001; pp. 27-39.

6. Galperin, P.Y. Sobre la formación de los conceptos y de las acciones mentales. In La Formación de las Funciones Psicológicas Durante el Desarrollo del Niño, 2nd ed.; Quintanar Rojas, L., Ed.; Universidad Autónoma de Tlaxcala: Tlaxcala de Xicohténcatl, México, 2001; pp. 45-56.

7. Galperin, P.Y. Acerca del lenguaje interno. In La Formación de las Funciones Psicológicas Durante el Desarrollo del Niño, 2nd ed.; Quintanar Rojas, L., Ed.; Universidad Autónoma de Tlaxcala: Tlaxcala de Xicohténcatl, Mexico, 2001; pp. 57-65.

8. Davidov, V.V. Tipos de Generalización en la Enseñanza; Pueblo y Educación: La Habana, Cuba, 1978. 
9. Davidov, V.V. Acerca do conceito de educação desenvolvimental. In Педагогика (Pedagogia), 1st ed.; Prestes, E., Translator; 1995.

10. Davidov, V.V. La Enseñanza Escolar y el Desarrollo Psíquico. Investigación Psicológica Teórica y Experimental; Editorial Progreso: Moscow, Russia, 1988.

11. Davidov, V.V. O que é a atividade de estudo. Rev. Esc. Inicial 1999, 7. Tradução do Russo de Ermelinda Prestes.

12. Repkin, V.V. Aprendizagem desenvolvimental e atividade de estudo. In Teoria da Atividade de Estudo: Contribuições de D. B. Elkonin, V.V. Davidov e V.V Repkin; Serie Ensino Desenvolvimental 10; Valdés Puentes, R., Ed.; Uberlândia Edufu: Curitiba, Brasil, 2019; Volume 1, pp. 365-406.

13. Repkin, V.V. A formação da atividade de estudo nos estudantes. In Teoria da Atividade de Estudo: Contribuições de D. B. Elkonin, V.V. Davidov e V.V Repkin; Serie Ensino Desenvolvimental 10; Valdés Puentes, R., Ed.; Uberlândia Edufu: Curitiba, Brasil, 2019; Volume 1, pp. 353-363.

14. Jara Holliday, O. Orientaciones Teórico-Prácticas para la Sistematización de Experiencias. Biblioteca Electrónica sobre Sistematización de Experiencias. 2011. Available online: https:/ / www.kaidara.org/recursos/orientaciones-teorico-practicas-para-lasistematizacion-de-experiencias/ (accessed on 20 December 2020).

15. Jara Holliday, O. La Sistematización de Experiencias: Práctica y Teoría para Otros Mundos Politicos, 1st ed.; Centro Internacional de Educación y Desarrollo Humano-CINDE: Bogotá, Colombia, 2018; 258p.

16. Colombia-MIN. Orientaciones Para Autores de Experiencias y Establecimientos Educativos; Proyecto: Las Rutas del Saber Hacer: Experiencias Significativas que Transforman la Vida Escolar, Guías No. 37; Panamericana Formas e Impresos S.A.: Buenos Aires, Argentina, 2010.

17. OEA; Agencia Interamericana para la Cooperación y el Desarrollo [AICD]. Manual de Capacitación sobre Registro y Sistematización de Experiencias Pedagógicas; Módulo 1, Proyecto: Estrategias y materiales Pedagógicos para la Retención Escolar; Ministerio de Educación Ciencia y Tecnología: Buenos Aires, Argentina, 2003.

18. UNESCO. Oficina de Lima. Sistematización de Experiencias Educativas Innovadoras; Serie Herramientas de apoyo para el trabajo docente; Cartolan E.I.R.L: Lima, Peru, 2016.

19. Elkonin, D.B. Atividade de estudo: Sua estrutura e formação. In Teoria da Atividade de Estudo: Contribuições de D. B. Elkonin, V.V. Davidov e V.V. Repkin; Serie Ensino Desenvolvimental 10; Valdés Puentes, R., Ed.; Uberlândia Edufu: Curitiba, Brasil, 2019; Volume 1, pp. 159-168.

20. Aquino, O.F.; Cunha, N.M. A tarefa de estudo: Ciência e criatividade do professor. Educ. Filos. 2015, 29, 125-152. [CrossRef]

21. Zambrano, J.; Laurencio, A.; López, A.; Estrada, O. Fundamentos del modelo para virtualización de la formación en la Universidad Técnica de Manabí, Ecuador. Atenas 2018, 4, 78-91.

22. Smith, J.; Guimond, F.A.; Bergeron, J.; St-Amand, J.; Fitzpatrick, C.; Gagnon, M. Changes in students' achievement motivation in the context of the COVID-19 pandemic: A function of extraversion/introversion. Educ. Sci. 2021, 11, 30. [CrossRef]

23. García-Pérez, L.; García-Garnica, M.; Olmedo-Moreno, E.M. Skills for a working future: How to bring about professional success from the educational setting. Educ. Sci. 2021, 11, 27. [CrossRef]

24. Davies, A.; Fidler, D.; Gorbis, D. Future Work Skills 2020; Institute for the Future for the University of Phoenix Research Institute: Palo Alto, UK, 2011; pp. 1-19. Available online: http:/ /www.iftf.org/futureworkskills2020 (accessed on 4 April 2021).

25. Román-Cao, E.; Delgado-Cedeño, L.A.; Pico-Mieles, J.G. La formación de habilidades como soporte del proceso de dirección del trabajo independiente. In Escenarios Educativos Latinoamericanos; Román, E., Ed.; Ediciones UTM: Portoviejo, Ecuador, 2019; pp. 53-66.

26. Ríos-Rodríguez, L.; Román-Cao, E.; Pérez-Medinilla, Y. Independent work management through adaptive teaching-learning environment APA-prolog. Rev. Electron. Educ. 2021, 25, 1-22. [CrossRef]

27. Román-Cao, E.; Herrera-Rodríguez, J.I. Aprendizaje centrado en el trabajo independiente. Educ. Educ. 2010, 13, 91-106. [CrossRef]

28. Medina-Zuta, P. Estado Actual de la Evaluación Formativa en la Educación Primaria. Fundamentos Científicos y Epistemológicos de Corrientes Científicas que Marcan Tendencia. Available online: https: / www.researchgate.net/publication/344466 384ESTADO_DEL_ARTE_EVALUACION_FORMATIVA (accessed on 10 June 2020).

29. Medina-Zuta, P.; Deroncele-Acosta, A. La evaluación formativa desde el rol del docente reflexivo. Maest. Soc. 2019, 16, 597-610.

30. Medina-Zuta, P.; Deroncele-Acosta, A. La construcción científico-textual en el posgrado: El desafío de la transdisciplinariedad y la reflexividad. Maest. Soc. 2019, 16, 829-838.

31. Organización para la Cooperación y el Desarrollo Económico-OCDE Creencias y prácticas pedagógicas. Teach. Focus 2015, 13.

32. SCImago Journal \& Country Rank. Ranking de Perú. Available online: https://www.scimagoir.com/rankings.php?country=PER (accessed on 10 June 2020). 